\title{
HISTÓRICO ABREVIADO DO INSTITUTO GEOLÓGICO, DE SUAS PUBLICAÇÕES E MAPAS
}

\author{
HAYDÉE POLITO PERIS *
}

\begin{abstract}
RESUMO
Este trabalho é um breve resumo sobre o histórico da Instituição, baseado em artigos e folhetos acerca do assunto, escritos por grandes nomes que passaram pelo antigo Instituto Geográfico e Geológico.

Também apresenta, um estudo das fases de editoração das publicações e mapas do Instituto, ao longo de sua vida.
\end{abstract}

\begin{abstract}
This paper is an abridgement about the Institution history, based in periodicals articles on the subject, written by respectable names who worked in the ancient Instituto Geográfico e Geológico.

Also presents a study about the various phases of the publications and maps edited by the Institution since its foundation.
\end{abstract}

\section{HISTÓRICO}

O atual Instituto Geológico, da Coordenadoria da Pesquisa de Recursos Naturais da Secretaria da Agricultura e Abastecimento do Estado de São Paulo, originou-se da antiga Comissão Geográfica e Geológica, que foi criada em 27 de março de 1886, sob a chefia do grande cientista norte-americano, Orville Adalberto Derby.

Como narra o Eng. Valdemar Lefèvre, em seu histórico da Comissão Geográfica e Geológica, publicado no períódico O IGG: Revista do Instituto Geográfico e Geológico, v. 18, n. 1, 1966. "na então Província de São Paulo, era Presidente' o Conselheiro do Império, João Alfredo Corrêa de Oliveira que observando a falta de informações referentes à geografia, recursos minerais, relevo topográfico, vias de comunicação, relativas à Província de São Paulo, sentiu a grande necessidade de criar uma Comissão, que iniciasse os estudos do território paulista."

"Em 27 de março de 1886 através da Lei n. 9, foi criada a Comissão Geográfica e Geológica, constituída pelos Eng ${ }^{\circ}$ S. Theodoro F. Sampaio e João F. Washington de Aguiar, para desenvolverem os trabalhos geográficos e Francisco de Paula Oliveira e Luiz F. Gonzaga de Campos, para desenvolverem os trabalhos geológicos."

"Os estudos de botânica e as observações meteorológicas ficaram sob a responsabilidade do botânico Alberto Löefgren."

"Foram os grandes cientistas citados, sob a direçã̃o de Orville A. Derby,

* Bibliotecária - Serviço de Comunicações Técnico-Científicas - Instituto Geológico. 
os pioneiros nos levantamentos geográficos e geológicos do Estado de São Paulo."

"Partindo da Comissão Geográfica e Geológica, desdobraram-se outras Instituições importantes da administração estadual, a saber: Instituto Florestal, ex-Horto Botânico da Cantareira, sob a chefia de Alberto Löefgren; Museu de Zoologia da USP. ex-Seção de Botânica e História Natural sob a chefia de Hermann Von Ihering; Instituto Astronômico e Geofísico da USP, ex-Seção de Meteorologia; Instituto de Botânica, ex-Seção de Botânica, sob a chefia de Alberto Löefgren, Museu Paulista, ex-Museu ou Coleção Sertório que pertenceu à Comissão, de início sob a chefia de Alberto Löefgren."

Como pudemos observar. a Província de São Paulo, contou no começo de seus trabalhos científicos com grandes nomes internacionalmente conhecidos.

A Instituição, na sua longa vida, sofreu muitas mudanças, decorrentes da evolução no campo das ciências.

\section{LEGISLAÇÃO}

A legislação referente à organização do Instituto Geológico desde a criação da Comissão Geográfica e Geológica é a que segue:

Lei n. 9 de 27 de março de 1886 - cria a Comissão Geográfica e Geológica, ligada ao Governo da Província de São Paulo.

Lei $n .^{\circ} 15$ de 11 de novembro de 1891 - orça a receita e despesa do Estado para o exercício de 1892 e organiza quatro Secretarias de Estado entre elas a Secretaria de Estado da Agricultura, Comércio e Obras Públicas. A partir dessa data a Comissão Geográfica e Geológica faz parte da estrutura da Secretaria de Agricultura.

Decreto n. 1459 de 10 de abril de 1907 - transfere o Serviço Meteoroló- gico da Comissão Geográfica e Geológica para a Diretoria de Agricultura da Secretaria da Agricultura Comércio e Obras Públicas.

Decreto n. 5.153 de 8 de agosto de 1931 - transfere a Comissão Geográfica e Geológica para a Secretaria de Estado dos Negócios da Viação e Obras Públicas.

Decreto n. ${ }^{\circ} 5.161$, de 12 de agosto de 1931 - organiza a Diretoria de Serviços Públicos e da Carta Geral do Estado da Secretaria da Viação e Obras Públicas e dá outras providências. Os serviços da Comissão Geográfica e Geológica ficam incorporados aos da Inspetoria dos Serviços Públicos para constituirem a Diretoria acima.

Decreto $n .^{\circ} 5.320$ de 30 de dezembro de 1931 - cria e dá organização ao Instituto Astronômico e Geográfico do Estado de São Paulo.

Decreto n. 7.309 de 5 de julho de 1935 - extingue o Instituto Astronômico e' Geográfico, criando o Departamento Geográfico e Geológico e restabelecendo o Instituto Astronômico e Geofísico, ambos dentro da Secretaria de Agricultura Comércio e Obras Públicas.

Decreto n. ${ }^{\circ} 9.871$ de 28 de dezembro de 1938 - reorganiza o Departamento Geográfico e Geológico da Secretaria de Estado dos Negócios da Agricultura, Indústria e Comércio e dá outras providências, passando a denominar-se Instituto Geográfico e Geológico.

Decreto n. 9.942 de 23 de janeiro de 1939 - aprova o Regulamento do Instituto Geográfico e Geológico.

Decreto n. ${ }^{\circ} 48.133$ de 20 de junho de 1967 - dispõe sobre a estrutura funcional e medidas para reforma administrativa da Secretaria de Estado dos Negócios da Agricultura - é criada a Coordenadoria da Pesquisa de Recursos Naturais, ficando o Instituto Geográfico e Geológico e 
outros Institutos da Secretaria, dentro da estrutura da Coordenadoria da Pesquisa de Recursos Naturais da Secretaria de Agricultura.

Decreto de 4 de novembro de 1969 - reorganiza o Instituto Geográfico e Geológico da Secretaria da Agricultura e dá outras providências correlatas.

Decreto n. 5.926 de 15 de março de 1975 - transfere órgãos da administração direta à vinculação de entidades descentralizadas e dá providências correlatas - O Instituto Geográfico e Geológico é transferido para a Secretaria de Economia e Planejamento.

Decreto n.० 6.822 de 26 de setembro de 1975 - altera a estrutura, subordinação e a denominação do Instituto Geográfico e Geológico da Secretaria de Economia e Planejamento. O Instituto Geográfico e Geológico, passa para a Secretaria de Agricultura com a denominação de Instituto Geológico, ficando a Divisão de Geografia com a Secretaria de Economia e Planejamento.

Decreto $n .^{\circ} 13.313$ de 13 de março de 1979 - dispõe sobre a organização da Secretaria de Economia e Planejamento do Gabinete do Governador e dá providências correlatas. A Divisão de Geografia passa a denominar-se Instituto Geiográfico e Cartográfico.

\section{ACERVO - BIBLIOTECA/MAPOTECA E MUSEU GEOLÓGICO}

\section{BIBLIOTECA/MAPOTECA}

Sendo a Instituição um órgão muito antigo da administração estadual, no acervo de sua Biblioteca/ Mapoteca existem obras de edições raras, na área de geologia e geografia e mapas antigos da cidade de São Paulo e Estado.

A Biblioteca/Mapoteca, possui 90.000 volumes entre livros, períódi- cos, folhetos, obras de referência, livros raros e 30.000 mapas.

A maior parte do acervo é obtido em base de permuta de publicações, estabelecida com Instituições congêneres internacionais.

As coleções de periódicos e livros abrangem as áreas de ciências puras e aplicadas, dando-se ênfase aos seguintes assuntos:

a) Ciências Puras: geologia, mineralogia, paleontologia, hidrologia, geodésia, cartografia, fotogrametria; química;

b) Ciências Aplicadas: mineração, engenharia hidráulica, engenharia sanitária, agricultura, engenharia çuímica, metalurgia;

c) Geografia Economica e Geral.

Através de seu material bibliográfico, a Biblioteca/Mapoteca, atende aos pesquisadores de geociências do Brasil e de várias partes do mundo.

O acervo da Mapoteca é constituído de:

a) Mapas da Cidade de São Faulo (desde a época do Império) Estado de São Paulo e de outros Estados do Brasil.

b) Mapas Internacionais: América do Sul, América do Norte, Europa, África e Ásia e alguns países e cidades dos quatro continentes.

\section{MUSEU GEOLÓGICO}

O acervo do Museu, baseado em minerais, rochas, minérios e fósseis na sua maioria do Estado de São Paulo, é decorrente da pesquisa geológica desenvolvida por um grupo de cientistas de grande gabarito internacional, como o já mencionado Orville A. Derby, Guilherme Florence, Hussak e nacionais como Theodoro Sampaio, Gonzaga de Campos e outros. 
Possui também uma coleção de rochas e minérios internacional, denominada "Coleção Krantz", adquirida há quarenta anos, na Alemanha.

A finalidade do Museu Geológico é principalmente didática divulgando as riquezas minerais do Estado de São Paulo e também de outros estados do Brasil.

O Museu está incumbido da conservação das Grutas Calcárias do Parque Estadual e Turístico do Alto Ribeira, situado no sul do Estado de São Paulo, na região de Iporanga e Apiaí no curso médio e alto do rio Ribera de Iguape, que recebe visitantes de todas as partes do Brasil.

\section{FASES DE EDITORAÇÃO DOS TRABALHOS DA INSTITUIÇÃO}

Pode-se dividir em três fases a editoração de trabalhos gerados pela Instituição, que constituem publicações e mapas:

a) 1.a Fase - Comissão Geográfica e Geológica

1886-1931 - A linha de atuação dos trabalhos publicados durante essa fase - Relatórios de Exploração de Rios, Relatórios de Atividades, Boletins e Mapas - abrange um campo mais amplo na área das ciências naturais. Além da geologia e geografia, foram publicados trabalhos sobre botanica, climatologia, etc.

Salienta-se nessa fase, os magníficos relatórios de exploração de rios do Estado de São Paulo e do litoral norte e sul do Estado, acompanhados de mapas e fotografias.

A Comissão Geográfica e Geológica, começou a publicar os Relatórios de suas Atividades, desde o ano de sua criação em 1886 e eram apresentados à Assembléia Legislativa Provincial de São Paulo. A partir de 1894-1904 os Relatórios começaram a sair publicados juntamente com os Relatórios da Secretaria de Agricultura, que foi criada em 1891. E de
1905 em diante, foram publicados individualmente pela própria Comissão.

A série Boletim, iniciou sua publicação em 1889, com o Boletim n.' 1 constituido da monografia de Orville A. Derby "Retrospecto histórico dos trabalhos geographicos e geologicos effectuados na Provincia de S. Paulo".

Os mapas elaborados pela Comissão Geográfica e Geológica, foram publicados em escala 1:100.000 e 1:200.000 - Folhas Topográficas, FoIhas Geológicas, Carta dos Excursionistas do Estado - e em escala $1: 1.000 .000$ e $1: 2.000 .000$ - Cartas Gerais e Geológicas do Estado de São Paulo.

No ano de 1887 foram iniciados os trabalhos para a elaboração da rede de triangulação, na cidade de Sorocaba, sendo em 1898 editado o mapa com o título de "Esboço da Zona Triangulada".

Em 1894 foi publicado o primeiro mapa do Estado de São Paulo pela Comissão, intitulado "Carta Progresso dos Trabalhos da Comissão Geographica e Geologica", apresentando a evolução cartográfica do Estado de São Paulo na época.

No mesmo ano, foi editado o volume "Plantas dos Relatórios apresentados ao Secretário de Agricultura", juntamente com a Superintendência de Obras Públicas e Fazenda de São João da Montanha.

Em 1914, a Comissão publicou a primeira planta da cidade de São Paulo com o título de "Planta Geral da Cidade de São Paulo, com Indicações Diversas", em escala 1:20.000.

O mapa que apresentava a declinação magnética do Estado, foi publicada em 1923, com a denominação de "Carta Izogônica do Estado de São Paulo".

A partir de 1923, as Cartas Gerais do Estado de São Paulo, já continham a indicação das divisas municipais. 
A série de mapas publicados em 6 Seções com o título de "Carta dos Excursionistas do Estado de São Paulo", foi editada no período de 1923-27, abrangendo a região do vale do Paraíba e arredores de São Paulo, indicando as vias férreas e rodovias.

Em 1930, foi editado o Boletim $n$. 22, escrito em inglês, pelo geólogo norte-amerioano Chester Washburne, que relata a sua pesquisa de petróleo no Estado de São Paulo, auxiliada grandemente pelos conhecimentos de Joviano A. Pacheco da Comissão Geográfica e Geológica. Anos depois $\mathrm{Pa}$ checo traduziu e ampliou o trabalho de Washburne, sendo publicado pelo Departamento Nacional da Produção Mineral.

b) 2.a Fase - Diretoria de Serviços Públicos e da Carta Geral do Estado (1930) - Instituto Astronomico e Geográfico (1930-35) - Departamento Geográfico e Geológico (19351938) - Instituto Geográfico e Geológico (1938-1969).

Divide-se em duas épocas:

1.a 1931-1938 - Os trabalhos publicados restringiram-se mais no âmbito da Cartografia, continuando a publicação das Cartas Gerais do Estaco, Mapas Geológicos e a série monográfica "Boletim". Foi iniciada a publicação de Notas Prévias e avulsos diversos que constituiam monografias também.

Podemos evidenciar entre as monografias o trabalho sobre a geomorfologia de São Paulo, acompanhado de muitas fotografias e mapas, publicado em 1932.

2.a 1939-1969 - Intensificado o levantamento cartográfico, foram publicados os Mapas Municipais do Estado de São Paulo, de acordo com as Leis de desmembramentos dos municípios, relativas aos anos de 1938, 1959, 1964 , em escala 1:100.000 e continuou a publicação das Cartas Gerais com os títulos de Carta Geográfica do Estado de São Paulo e Mapa da Divi- são Administrativa e Judiciária do Estado, ambas em escala 1:1.000.000.

Em 1943, foi publicada a "Carta Hipsométrica do Estado", em escala $1: 1.000 .000$, apresentando por coloração as elevações do Estado e um quadro dos pontos culminantes nas serras principais e altitudes de cidades do Estado.

Em 1950, foi impresso em traço azul, um mapa do Estado de São Paulo, apresentando as bacias hidrográficas em escala 1:750.000.

A coleção de 11 Folhas Topográficas do Estado de São Paulo, em escala 1:250.000 foi editada em 1954, sendo a primeira vez que uma coleção de mapas do Estado foi publicada nessa escala.

Quanto às publicações, continuou a ser editada a série "Notas Prévias", perfazendo um número de cinco, constituindo trabalhos muito importantes nas áreas da geodésia, paleontologia, com a divulgação de novos fósseis do Estado de São Paulo, descobertos pelo paleontológo da Instituição.

Dentre os avulsos diversos, salienta-se a monografia que indica as ocorréncias minerais do Estaldo de São Paulo, único trabalho desse gênero editado até agora e muito procurado por estudantes.

Os trabalhos de maior significação dos técnicos do IGG, foram publicados nesse período na série "Boletim".

Apontamos os seguintes Boletins:

n. 34 - referente às coordenadas geográficas de locais do Estado de São Paulo,, sendo base para o mapeamento do Estado e muito importante para a definição da rede rodoviária do Estado;

n. 37 - nivelamento geral do Estado de São Paulo, com as altitudes de precisão; é suporte para qualquer trabalho de altimetria até os dias de hoje. 
n. 38 - apresenta a definição de um método do autor para o estabelecimento de azimutes.

n. 39 - elaboração de um programa de estudos dos recursos hídricos do Valle do Paraíba, por um especialista americano, atendendo a um convênio com o DAEE, e com a ajuda dos técnicos da Instituição, cujo produto foi publicado no Boletim n. 42 de autoria dos geólogos do IGG.

n. 41 - versa sobre a geologia do Estado de São Paulo e esgotou prematuramente pela sua grande utilidade aos estudantes de geologia.

n. 35 e n. 40 - levantamento bibliográfico da geologia do Estado de São Paulo, abrangendo um período de 1952-1962, muito necessário para os pesquisadores da área. Publicação que deveria continuar sistemáticamente.

n. 45 - apresenta a distribuição dos fósseis no Estado de São Paulo de maneira didática, constituindo o único trabalho escrito no gênero.

O periódico o IGG: Revista do Instituto Geográfico e Geológico, começou a ser editado em 1943 e cessou a sua publicação em 1968 com o vol. 20.

Apresentava artigos abrangendo a área de geografia com descrição de vários municípios do Estado de São Paulo e também sobre a geologia, geodésia, históricos da CGG, relatórios das atividades da Instituição e biografias de técnicos e funcionáros do Instituto que se aposentavam.

E finalmente em 1960 foi inciado o levantamento aerofotogramétrico do Estado em caráter sistemático pelos técnicos do IGG, dando início à publicação de Folhas Topográficas em escala 1:50.000, totalizando 411 mapas, $\mathrm{do}_{\mathrm{S}}$ quais 109 foram impressos pelo Serviço Cartográfico Militar dos Esdos Unidos e 302 pela Fundação IBGE.

c) 3.a Fase - Instituto Geográfico e Geológico e Instituto Geológico.

Divide-se em duas épocas:

\section{1.a 1970-75 - Instituto Geográfi- co e Geológico}

Continua a publicação das monografias seriadas "Boletins" que contém trabalhos sobre geologia, paleontologia, pesquisas de minerais e das Folhas Topográficas do Estado em escala 1:50.000.

Em 1971/72 foram publicados doi $_{S}$ mapas das Cidades de Santos e São Vicente em escala 1:10.000 e lima coleção de nove mapas da Cidade de São Paulo, em escala 1:12.500.

Nessa época continuou a edição dos Relatórios Anuais das Atividades do Instituto e é iniciada a publicação do Boletim Mensal da Biblioteca, que relaciona o material bibliográfico livros, folhetos, periódicos mapa $_{\mathrm{S}}$ entrados no acervo durante o mês.

Em 1974, os Mapas Geológicos e Mapas com a divisão administrativa e judiciária do Estado, em escala 1:1.000.000 foram reeditados.

2.a De 1976 em diante - Instituto Geológico.

Apesar da Instituição ter sofrido um desmembramento que a prejudicou muito, perdendo a Divisão de Geografia, foram publicados vários trabalhos.

Iniciadas $a_{S}$ publicações de monografias em novas séries, a saber:

Avulsos - trabalhos menos extensos abrangendo a geologia, hidrogeologia, mineralogia, modelo matemático aplicado à hidrogeologia, e resumo histórico da Instituição. Alguns

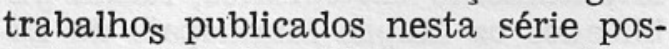
teriormente são editados como artigos na Revista do Instituto Geológico.

Boletins - Os Boletins da nova série, especificam assuntos de petrologia, hidrogeologia e aplicação de modelos matemáticos para escoamento 
de bacias hidrográficas; este último, atendendo a um projeto da Secretaria da Agricultura e Abastecimento denominado "PROMOJI".

Monografias - apresentam relatórios de projetos desenvolvidos pela Instituição, o único publicado nesse período é um Projeto de Ȧgua Subterrânea, contribuindo para o Programa de Zoneamento Agrícola do Estado de São Paulo. desenvolvido pela Secretaria de Agricultura e Abastecimento.

Em 1980, foi iniciada uma nova edição do periódico O IGG, com a denominação de Revista do Instituto Geológico, Rev. IG.

É uma publicação semestral, composta de vários artigos, escritos por pesquisadores e técnicos da Instituição ou de fora, abrangendo sempre a área de geociências.

No âmbito da Cartografia Temática, foi iniciada a publicação de Folhas Geológicas de Formações Superficiai $_{S}$ em escala 1:50.000, baseadas nas Folhas Topográficas do Estado de São Paulo, já publicadas na mesma escala.

As referidas Folhas Geológicas, representam um levantamento pioneiro da Instituição e talvez do Brasil, no campo da geociências, aliando a geologia estratigráfica com informações sobre a granulometria $\mathrm{da}_{\mathrm{s}}$ rochas superficiais.

A Folha Geológica com Formações Superficiais tem aplicações práticas na áreas de : construção de barragens, fundações, rodovias, ferrovias; na agricultura, silvicultura, geologia ambiental e de apoio aos estudos geográficos e geomorfológicos.

No final deste artigo, é apresentada a lista bibliográfica de todos os trabalhos e mapas editados pela Instituição desde a sua criação até os dias de hoje.

\section{SITUAÇÃO ATUAL - PROJETOS EM DESENVOLVIMENTO}

O último desmembramento como evidencia a legislação, dividiu o então Instituto Geográfico e' Geológico, estruturado em bases científicas de grande valor, contribuindo com trabalhos de alto padrão na cartografia e geologia do Estado de São Paulo, para uma nova estrutura e denominação, surgindo o Instituto Geológico.

Atualmente a Instituição está envidando grandes esforços no sentido de desenvolver quatro grandes projetos dentro de sua linha de atribuições:

a) - "Levantamento Geológico das Formações Superficiais no Estado de São Paulo" - cuja finalidade principal é subsidiar trabalhos relacionados ao problema da erosão acelerada. Referente a esse projeto, já foi publicada a Folha Geológica de Formáções Superficiais de Leme em escala 1:50.000 e estão em preparação as Fo-

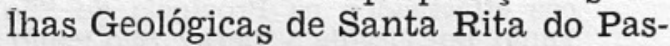
sa Qautro, Piraçununga, Aguaí, São João da Boa Vista, Casa Branca e Rio Capetinga;

b) - "Racionalização dos Serviços de Perfuração e Captação de Águas Subterrânelas, para um melhor Atendimento aos Municípios do Estado de São Paulo"; sendo que, de 1971-1980 foram perfurados 163 poços num total de 14.564 metros.

c) - "Avaliação do Potencial dos Recursos Hídricos Subterrâneos na Região de Tietê, Cerquilho e Porto Feliz" - seu objetivo primordial é fornecer condições de solucionar problemas de abastecimento urbano em termos de recursos hídricos;

d) - "Pesquisa Sistemática dos Recursos Minerais no Vale do Ribeira de Iguape" - finalidade mais impor-

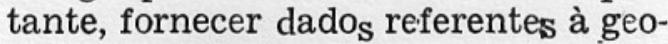
logia econômica para um melhor aproveitamento dos recursos minerais do Estado de São Paulo. 
Os projetos mencionados constatam uma grande aplicação à resolução de problemas emergentes do Estado de São Paulo e o Instituto Geológico está desenvolvendo-os, apesar das dificuldade ${ }_{S}$ quanto à carência de recursos humanos o que tem impossibilitado um atendimento mais am-

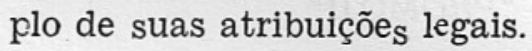

\section{AGRADECIMENTOS}

Agradecemos os esclarecimentos técnicos do Eng. Moacyr de Carvalho, que nos ajudou na descrição dos Boletins da área de geodésia e mapas antigos.

Agradecemos também a colaboração das Bibliotecárias Maria Christina Cardoso de Almeida e Sonia Maria Rebouças que transformaram a lista de publicações em referências bibliográficas e Kioko Kusuki de Oliveira que datilografou o trabalho.

\section{BIBLIOGRAFIA}

COMISSÃO GEOGRAFICA E GEOLÓGICA - 1887 - Relatório. São Paulo. 33 p.

$13 \mathrm{p}$. - 1892 - Relatório. São Paulo.

- 1889 - Retrospecto histórico dos trabalhos geographicos e geológicos effectuados na Província de São Paulo, por Orville A. Derby. São Paulo. 26 p. (Boletim, 1).

FELICISSIMO JR., J. - 1951 - Centenário do nascimento de Orville Derby. O IGG: Rev. Inst. Geogr. Geol., São Paulo, 9(3):110-125, jul./set.

1969 - Instituto Geográfico e Geológico. Dig. Econ., São Paulo, 42 (206):83-93, março/abr.

LEFEVRE, V. - 1951 - Comemorações do centenário do nascimento de Orville A. Derby. O IGG: Rev. Inst. Geogr. Geol., São Paulo, 9(3):108-109, jul./set.

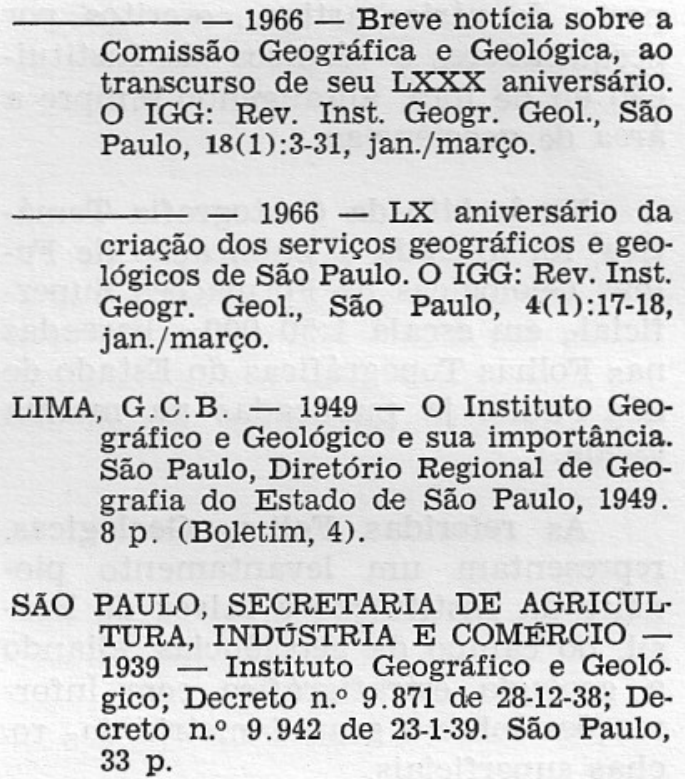
Comissão Geográfica e Geológica, ao transcurso de seu LXXX aniversário. O IGG: Rev. Inst. Geogr. Geol., São Paulo, 18(1):3-31, jan./março. criação dos serviços geográficos e geológicos de São Paulo. O IGG: Rev. Inst. Geogr. Geol., São Paulo, 4(1):17-18, jan./março. ráfico e Geológico e sua importância. São Paulo, Diretório Regional de Geografia do Estado de São Paulo, 1949. 8 p. (Boletim, 4). 1939 - Instituto Geográfico e Geoló. gico; Decreto n. 9.871 de 28-12-38; De$33 \mathrm{p}$. 